* Corresponding author

Phone +421556022458

E-mail address: frantisek.simcak@tuke.sk

(prof. Ing. František Šimčák, CSc.)

Article information

Article history: AMS-Volume16-No.2-00162-12

Received 14 January 2012

Accepted 25 July 2012

\section{Analysis of Stress Fields Relate to Plastic Deformation of the Steel Sheets}

\author{
Michaela Štamborská, František Šimčák* \\ a Department of Applied Mechanics and Mechatronics, Faculty of Mechanical Engineering, Letná9, 04200 Košice, Slovak Republic
}

\section{BIOGRAPHICAL NOTES}

prof. Ing. František Šimčák, CSc. he is a professor of applied mechanics, Deputy head of the Department of Applied Mechanics and Mechatronics. He is author of 4 monographs, 8 university textbooks, 6 university notebooks and more than 200 publications in journals and conference proceedings at Slovakia and abroad. He has been worked on many grant projects, research tasks and projects for industry.

Ing. Michaela Štamborská

\section{KEY WORDS}

strain fields, stress fields, virtual fields method, finite element method

\section{ABSTRACT}

TThe article is focused on identification the stress fields related to strain fields by using digital image correlation $(\mathrm{DIC})$ and to verify the results obtained using the finite element method (FEM). Particular attention is devoted to the analysis of deformation in area of stress concentration (near notch). The virtual field method is using to determine the stress fields connected with displacement fields, which was elaborated for analysis of an elasto plastic deformation by Grédiac and Pierron. These procedures are applied to determine the properties of cold rolled steel used for automobile industry. For analysis was used uncoated sheet of isotropic steel with higher strength properties.

\section{Introduction}

The effective support systems having a high load capacity and low weight is possible to create by using thin-walled elements. Identification and quantification of plastic deformation in thin-walled structural elements is important for localizing the places of possible violations [1]. It allows prediction of failures particularly in areas of stress concentration and is a source of information for assessing the durability of structural elements of structures [2], [3]. Cold forming of steel sheets is very often applied in the manufacture of moldings and enables to obtain different shapes and sizes of specimens which are most often used in automotive and consumer industries, construction etc. In order to reduce weight of bearing systems are recently widely used new steels, which are characterized by increased strength characteristics. The article is focused on identification the stress fields related to strain fields by using digital image correlation (DIC) and to verify the results obtained using the finite element method (FEM) [4], [5].

\section{Selected Methods of Processing}

For the experimental analysis was applied DIC method by using a 3D procedures, 
while some measurements were performed at Arts et Métiers ParisTech in Châlons-en-Champagne (France).

For the processing of measurement results was used the virtual fields method in the application of the programs Vic 3D, Camfit, Matlab, Cosmos DesignStar and Abaqus. Parameters obtained by Camfit were used in the Matlab to determine the stress fields from the strain fields of steel sheets. Then stress fields thus obtained were compared by finite element method.

In the case of classical visual correlation are deformations of an object for observation obtained by CCD camera. In the process of digital image correlation determines the displacement and / or rotation and curvature of small elements called facets, determined in the reference image. Correlation algorithms can determine the point of maximum displacement with accuracy up to 1/100 pixel2. This approach enables the identification of the object deformation in a parallel plane to plane of the camera image. The spatial deformation analyses are used by two cameras. When an object is observed from two different directions, the position of each object point is focused on a pixel in the plane of the camera. If the position of both cameras to each other, zoom lenses and all the image parameters are known, we can calculate the absolute three-dimensional coordinates of each point on the surface of an object in space (Fig. 1).

If coordinates of all points of the surface of the object are known, we can determine the spatial contour of the surface in all areas observed by both cameras.

The structure of the object must be sufficient to be able to correlate the identical points of both cameras. Therefore we need before the measurement sprayed black and white paint structure on the surface of the specimen (Fig. 1).

The correlation algorithm is based on the gray values of the model structure monitoring. Once the spatial shape is determined, then the next step is determination of three-dimensional deformation of the object surface. This process is performed by correlation of the images, captured by both cameras at each step of measuring with reference frames captured for example at zero step.

Fig. 2 shows the element displacement vector of the object surface. Center $P$ was shifted from the reference position to the deformed position $v$. In addition, the element surface was rotated, inclined and curved. If displacement vectors of all points and reference outline are known, then it is possible to calculate the relative deformation. These can be determined directly by derivative of adjoining points displacements or by analysis of local facets bending, which were used to correlation.



Fig. 1: The principle of a 3D image correlation with two cameras.

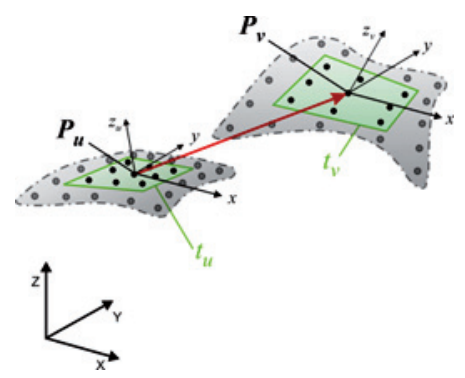

Fig. 2: Determination of the displacement vector.

For the solution was applied the virtual fields method, which Camfit program uses to determine the results obtained from an experimental procedure to identify the material properties of sheet metal. The most of the elaboration of this method and its application to solving problems of stress and deformation analysis deserved Grédiac and Pierron, and its theoretical foundations and principles are described in detail in the literature [6].

Let's present the procedure listed above on notched specimen (Fig.3), which was used for experimental analysis of strain and stress fields in the elasto plastic area. 


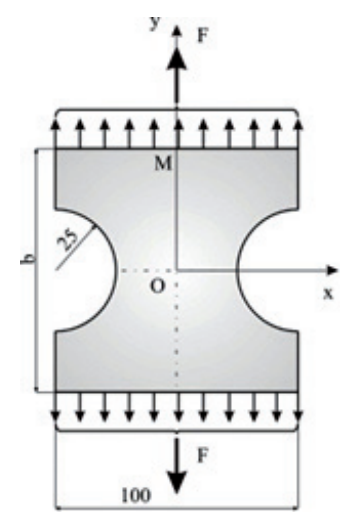

Fig. 3: Determination of the displacement vector.

Suppose that the sample is loaded with tensile force $F$ acting on its axis. Due to the symmetry we choose coordinate system beginning in the middle of the sample. For simplicity, we assume that the sample material is isotropic. So by the previous procedure we will determine two material parameters (physical constants), D11 and D12, provided that samples have constant strain along their thickness. For this case it is necessary to choose two kinematically admissible virtual fields for the virtual displacements $\delta u(1)$ and $\delta u(2)$. The first very simple virtual field define fields of virtual displacement in the direction of load and for this case is for equation (1)

$$
\begin{array}{ll}
\delta \mathrm{u}_{\mathrm{x}}^{(1)}=0, & \delta \varepsilon_{\mathrm{x}}^{(1)}=0, \\
\delta \mathrm{u}_{\mathrm{y}}^{(1)}=\mathrm{y}, & \delta \varepsilon_{\mathrm{y}}^{(1)}=1, \\
& \delta \gamma_{\mathrm{xy}}^{(1)}=0 .
\end{array}
$$

The second virtual displacement field is chosen so that it is independent of the first virtual displacement field, which are intended relationships (2).

$$
\begin{array}{ll}
\delta \mathbf{u}_{\mathrm{x}}^{(2)}=\mathrm{x}(\mathrm{y}+50)(\mathrm{y}-50) & \delta \varepsilon_{\mathrm{x}}^{(2)}=(\mathrm{y}+50)(\mathrm{y}-50) \\
\delta \mathrm{u}_{\mathrm{y}}^{(2)}=0, & \delta \varepsilon_{\mathrm{y}}^{(2)}=0 \\
& \delta \gamma_{\mathrm{xy}}^{(2)}=2 \mathrm{xy} .
\end{array}
$$

If we apply the virtual displacement fields for equations (1) and (2) in relation

$$
\int_{A}\left(\sigma_{x} \delta \varepsilon_{x}+\sigma_{y} \delta \varepsilon_{y}+\tau_{x y} \delta \gamma_{x y}\right) d A=\int_{s}\left(p_{x} \delta \mathrm{u}_{\mathrm{x}}+p_{y} \delta \mathrm{u}_{\mathrm{y}}\right) d s,
$$

which embodies the principle of virtual work, we get two equations of the form

Relations (3) and (4) indicate a set of two independent linear equations for the calculation of the unknown material parameters D11 and D12.

$$
\begin{aligned}
& D_{11} \int_{A} \varepsilon_{y} d A+D_{12} \int_{A} \varepsilon_{x} d A=F b \\
& D_{11} \int_{A}\left(\varepsilon_{x}(\mathrm{y}+50)(\mathrm{y}-50)+\gamma_{x y} 2_{x y}\right) d A+ \\
& D_{12} \int_{A}\left(\varepsilon_{y}(\mathrm{y}+50)(\mathrm{y}-50)-\gamma_{x y} 2_{x y}\right) d A=0 .
\end{aligned}
$$

\section{Measuring by Two CCD Cameras}

For the analysis of deformation of thin-walled elements was selected notched specimen with the geometry and dimensions as shown in the Fig. 4.
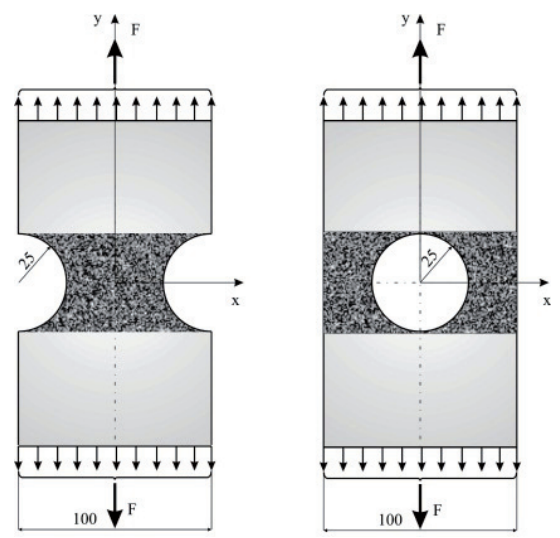

Fig. 4: Shape and dimensions of the notched specimen.

The mechanical properties of the notched specimen obtained by tensile test in the direction of rolling are shown in the Tab. 1. Specimen was made from isotropic steel, which is characterized by increased strength properties.

Table 1: Mechanical properties of specimen.

\begin{tabular}{|l|l|l|l|l|l|l|l|}
\hline Thickness [mm] & $\begin{array}{l}\mathbf{R}_{\text {po,2 }} \\
{[\mathbf{M P a}]}\end{array}$ & $\begin{array}{l}\mathbf{R m} \\
{[\mathbf{M P a}]}\end{array}$ & $\begin{array}{l}\mathbf{A 8 0} \\
{[\%]}\end{array}$ & $\begin{array}{l}\mathbf{A g} \\
{[\%]}\end{array}$ & $\mathbf{r}$ & $\mathbf{n}$ \\
\hline 0,8 & 229 & 339 & 35 & 20,6 & 1 & 0,19 \\
\hline
\end{tabular}

Measurements were realized at Arts et Métiers ParisTech in Châlons-en-Champagne (France) by two high-speed CCD cameras JAI Pulnix TM - 4000 $\mathrm{CL}$, which measured displacement fields on the surface of notched specimen, which was loaded by a hydraulic tensile machine INSTRON 8801 [7]. 
Strain fields $\varepsilon_{x^{\prime}} \varepsilon_{y}$ and $\gamma_{x y}$ obtained by software Vic 3D are shown in the Fig. 5.
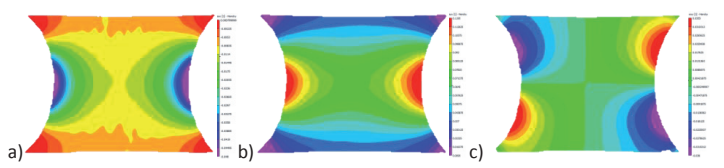

Fig. 5: Shape and dimensions of the notched specimen.

Strain fields $\varepsilon_{y}$ in the gradual increase in all range of movement of traverse, which allows us to monitor the development of plastic deformation in notched specimen are shown in the Fig. 6.
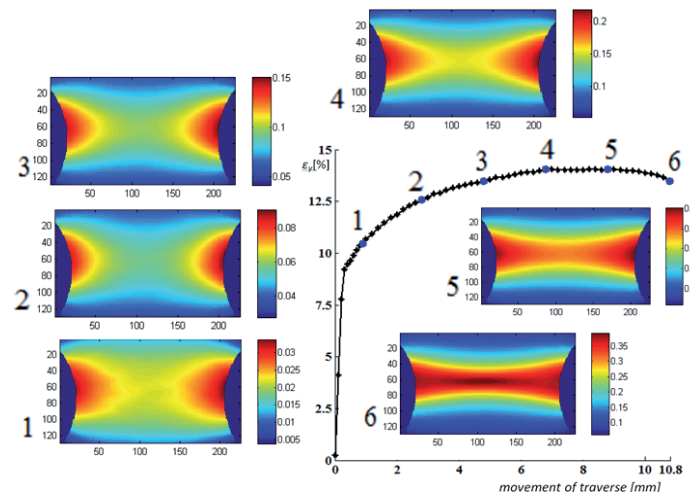

Fig. 6: Strain fields $\varepsilon_{y}$ for notched specimen in all range of movement of traverse.

The results obtained by DIC were then processed by Camfit [8], which is a GUI Matlab ${ }^{\oplus}$ based software implementing the Virtual Fields Method. It can deal with linear elasticity (isotropic and orthotropic) as well as simple elastoplasticity. Theoretical background of the virtual fields method is given in [9], [10].

Values of displacements ux and uy were exported from Vic 3D and they correspond to values of forces in each slide. The strain fields $\varepsilon x$, cy and $p x y$ (Fig. 7) were calculated from this displacement fields and they can be compared with those obtained by Vic 3D (Fig. 5).
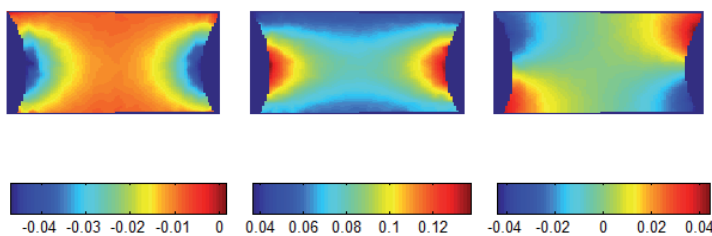

Fig. 7: Strain fields $\varepsilon_{x}, \varepsilon_{y}$ and $y x y$ obtained by Camfit
In the first phase Camfit identifies material parameters in the elastic area (Young's modulus and Poisson's ratio). The second phase concerns the identification of parameters in the plastic area, while the program allows to use a few hardening models.

Values obtained for notched specimen by hardening law

$$
\sigma_{H(k)}=X_{1} \cdot\left(X_{2}+\varepsilon_{e q p l(k)}\right)^{X_{3}},
$$

are shown in the Tab. 2 utilizing the energy principle, where $\sigma_{H(k)}$ is equivalent stress and $X_{1}, X_{2}, X_{3}$ are valuesobtained by Camfit in elasto plastic area in the whole measurement process.

Comparing the results shown in Tab. 2 and Tab. 1 we can see that the yield stress obtained by Camfit for elasto plastic area is essentially identical to the yield stress obtained by normalized tensile test. Other obtained parameters of the sheet material properties of plastic deformation listed in the Tab. 2 are used as an input for the identification of stress fields in the elasto plastic area [11].

Table 2: Mechanical properties of notched specimen.

\begin{tabular}{|l|l|l|l|}
\hline \multicolumn{4}{|c|}{ Results obtained by Camfit } \\
\hline$R_{e}$ & $X_{1}$ & $X_{2}$ & $X_{3}$ \\
\hline 229,1 & 842,7 & 0,104 & 0,575 \\
\hline
\end{tabular}

Parameters obtained by Camfit in elasto plastic area were processed by Matlab [12] and course of stress field oy for this specimen is shown in the Fig. 8.

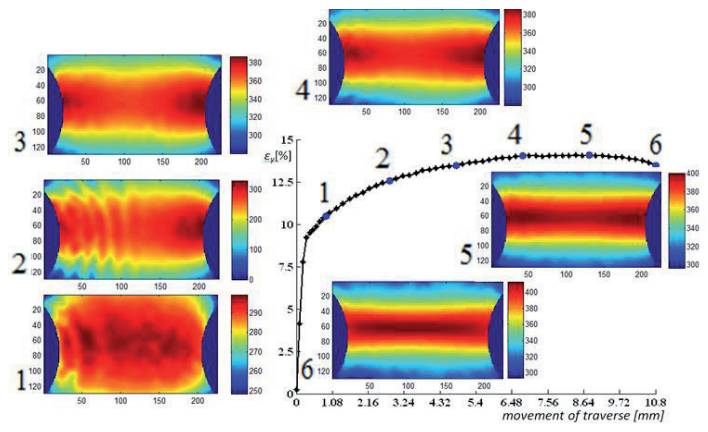

Fig. 8: Stress fields oy depending on movement of traverse.

Stress fields $\sigma x, \sigma y$, txy obtained by Matlab for displacement $3.8 \mathrm{~mm}$ [13], [14] are shown in the Fig. 9.

Within the problem solution a comparative numerical calculations of stresses in an elasto plastic 
area for the isotropic material using the von Mises model was realized. In Fig. 10 are given results of field stress $\sigma x, \sigma y, \tau x y$, obtained by Cosmos DesignStar under the load of sample at force adequate to displacement traverse $3,8 \mathrm{~mm}$.
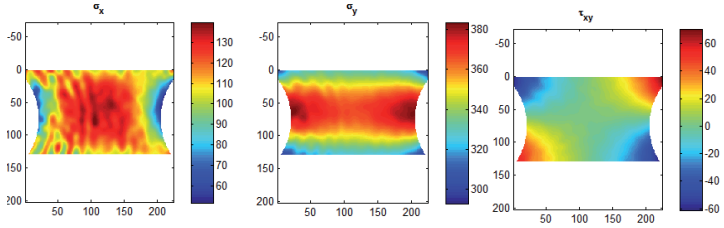

Fig. 9: Stress fields obtained from the strain fields.

Within the problem solution a comparative numerical calculations of stresses in an elasto plastic area for the isotropic material using the von Mises model was realized. In Fig. 10 are given results of field stress $\sigma \mathrm{x}, \sigma \mathrm{y}, \tau \mathrm{xy}$, obtained by Cosmos DesignStar under the load of sample at force adequate to displacement traverse $3,8 \mathrm{~mm}$.

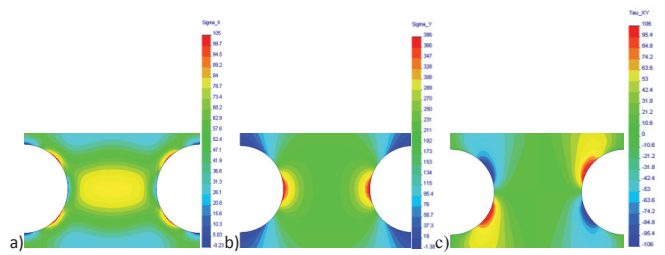

Fig. 10: Stress fields a) $\sigma_{x}$ b) $\sigma_{y}$ c) $\tau_{x y}$ obtained by Cosmos DesignStar.

Results of the stress fields $\sigma x$, oy and txy obtained by Abaqus for load which corresponds to the displacement traverse $3.8 \mathrm{~mm}$ are shown in the Fig. 11. Consequently, it is impossible to compare results obtained numerically shown in Fig. 10 and Fig. 11 with results obtained from experiments which are shown in the Fig. 9.

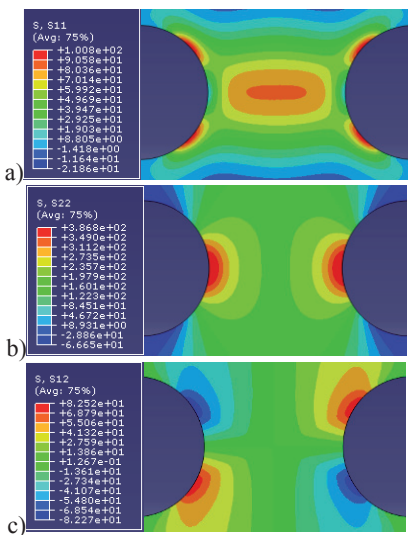

Fig. 11: Stress fields a) $\sigma_{x}$ b) $\sigma_{y}$ c) $\tau_{x y}$ obtained by Abaqus.

\section{Conclusion}

For the determination of strain fields on the sample surfaces was used digital image correlation and scanning frequency was defined as one frame at one displacement of traverse. Before realization of experiment classical standardized tensile tests were accomplished, where was obtained the yield stress of given materials and material properties listed in Tab.1. The results of yield obtained by Camfit were compared with those obtained from tensile tests. Comparing the results of yield stress values obtained by Camfit with yield stress obtained from conventional tensile tests shows very good agreement, this confirms the suitability of the virtual fields method for determining material properties of samples made from sheet metal.

Comparing the experimental and numerical results for material shows good agreement of values for stress fields oy (difference max. 5\%) while the differences of maximum stress values $\sigma x$ and txy are up to $35 \%$.

\section{Acknowledge}

The paper has been created realization of project "Center for research of control of technical, environmental and human risks for permanent development of production and products in mechanical engineering" (IMTS:26220120060), based on operating program support Research and Development financed from European Regional Development Fund and by Scientific Grant Agency VEGA MŠ SR for the support of this work under Project No. 1/0289/11.

\section{References}

[1] Šimčák F., Berinštet V., Štamborská M.: Some possibilities of determination of yield conditions for cold rolled steel sheets - 2010. In: Acta Mechanica Slovaca. Vol. 14, no. 4, p. 28-35. ISSN 1335-2393

[2] Härkegård, G. - Mann, T.: Neuber Prediction Of Elastic-Plastic Strain Concentration In Notched Tensile Specimens Under Large-Scale Yielding, Department Of Machine Design And Materials Technology, Norwegian University Of Science And Technology, Trondheim, Norway, J. Strain Analysis, Vol. 38 No. 1 S02702 @ Imeche 2003

[3] Fillipini, M.: "Stress Gradient Calculations At Notches," International Journal Of Fatigue, Vol. 22(5), Pp. 397-409, 2000.

[4] Strang, G. - Fix, G.J.: An Analysis OfThe Finite Element Method. Automatic Computation. Prentice-Hall, New Jersey, 1973.

[5] Trebuňa, F. - Šimčák, F.: Príručka experimentálnej mechaniky, Košice 2007, Isbn 970-80-8073-816-7. 
[6] Pierron, F. - Grédiac M.: The Virtual Fields Method. Springer, June 29, 2011.

[7] http://pdf.directindustry.com/pdf/instron/8801-fatiguetesting-systems/18463-138042-_8.htm|\#

[8] http://www.camfit.fr/downloads.php

[9] Avril, S. - Grédiac, M. - Pierron, F.: Sensitivity Of The Virtual Fields Method To Noisy Data. Comput. Mech., 34(6):439452, 2004

[10] Grédiac, M. - Pierron, F.: Applying The Virtual Fields Method To The Identification Of Elasto-Plastic Constitutive Parameters. Int. J. Plasticity, 22:602-627, 2006.

[11] Sutton, M.A. - Deng, X. - Liu, J. - Yang, L.: Determination of Elastic-Plastic Stresses And Strains From Measured Surface Strain Data. Experimental Mechanics, 36(2):99-112, 1996.

[12] http://books.google.com/books?id=52v7jea3aqic\&pri

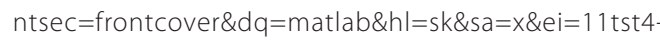
nky6l4gtqlsm_ag\&ved=0cdgq6aewaq $\#$ v $=$ onepage $\& q=m a$ tlab\&f=true

[13] Swift, H.W.: "Plastic Instability Under Plane Stress", Journal Of The Mechanics And Physics Of Solids, Vol. 1, 1952, Pp. 1-18.

[14] Wang, J. - Levkovitch, V. - Reusch, F. - Svendsen, B.: Modeling And Simulation Of Directional Hardening In Metals During Non-Proportional Loading; Journal Of Materials Processing Technology 176, 2006, 430-432. 